Osmar Colas ${ }^{1}$

Nicole Moraes Rego de Aquino²

ROSIANE MATTAR ${ }^{3}$

Editorial

\section{Ainda sobre o abortamento legal no Brasil e o conhecimento dos profissionais de saúde}

\section{Legal abortion in Brazil and the knowledge of health professionals}

Desde 1989, com a criação do primeiro programa público de interrupção da gestação nos casos previstos em lei no município de São Paulo ${ }^{1}$ o tema "aborto legal" tem sido motivo de muitas e polêmicas discussões. Estas permitiram observar crenças não verdadeiras por parte dos profissionais da saúde, além de graus diversos de desconhecimento a respeito dos aspectos médicos e legais envolvidos na assistência que deve ser prestada à vítima de violência sexual.

Por outro lado, conflitos religiosos, sociais, familiares e sexuais dificultam, muitas vezes, o posicionamento da equipe de saúde frente à prestação de uma assistência justa e humana a estas mulheres. Em 1996, diante das dificuldades enfrentadas por entidades públicas para a implementação de programas de assistência às vítimas de violência sexual, particularmente à interrupção legal da gestação, o Centro de Pesquisas Materno-Infantis de Campinas (Cemicamp), juntamente com a Federação Brasileira das Associações de Ginecologia e Obstetrícia (Febrasgo) e o Ministério da Saúde, passou a coordenar uma série de fóruns interprofissionais para discussão do tema ${ }^{2}$. $\mathrm{O}$ intuito era o de divulgar, sensibilizar, criar estratégias e colaborar na implementação destes programas em todo o país.

A partir desta época, praticamente todos os congressos, jornadas e atividades afins passaram a incluir o tema "aborto legal" em sua programação, ensinando a médicos e alunos de Medicina os aspectos clínicos, cirúrgicos e legais da assistência às vítimas de estupro bem como a abordagem à interrupção de gravidez prevista em lei.

Para analisar o resultado deste esforço e garantir bom atendimento às vítimas de violência sexual, houve a proposição de avaliar não só os efeitos das atividades educativas e didáticas mencionadas acima, mas também os resultados de reflexões que os profissionais de saúde vêm elaborando sobre o tema nestes anos.

\footnotetext{
Mestre em Ciências pelo Departamento de Obstetrícia da Universidade Federal de São Paulo - UNIFESP - São Paulo (SP), Brasil.

2 Pós-graduanda do Departamento de Obstetrícia da Universidade Federal de São Paulo - UNIFESP - São Paulo (SP), Brasil.

${ }^{3}$ Livre-Docente, Professor Associado do Departamento de Obstetrícia da Universidade Federal de São Paulo - UNIFESP - São Paulo (SP), Brasil.
} 
Alguns trabalhos com este enfoque foram realizados, em que se compararam o conhecimento e a opinião de médicos tocoginecologistas a respeito do abortamento inventariados em duas ocasiões: $2004^{3}$ e $2007^{4}$. A metodologia utilizada teve a intenção de observar a "evolução" (modificações de conhecimento, sensibilidade e percepção do tema) acontecida após as várias atuações de profissionais comprometidos com o tema nos congressos, jornadas, fóruns, cursos, etc.

Foi constatada uma interessante evolução de conhecimento acerca dos direitos das mulheres, das leis que envolvem a problemática das interrupções da gestação, dos documentos necessários e até no entendimento da necessidade de ampliação das indicações legais para a interrupção da gestação. Entretanto, verificou-se haver ainda alguma confusão a respeito de quais documentos e de quem deve estar envolvido na solicitação de interrupção da gravidez, principalmente nos casos de menores, o que reforça a necessidade do ensino e da participação de profissionais que trabalhem com os aspectos legais relacionados ao ato.

Mais do que somente o ensino das leis e normas que regem, no Brasil, a possibilidade de interrupção das gestações, a abertura de fóruns para discussão deste assunto determina reflexões e sensibiliza os que deles participam.

Estas observações reforçam achados anteriores ${ }^{6}$, que indicaram ser o desenvolvimento da capacidade de comprometimento e respeito ao outro um dos fatores que com maior prioridade devem ser trabalhados entre os profissionais de saúde que prestam assistência às mulheres que solicitam interrupção da gravidez por motivos previstos em lei, a despeito das rotulações jocosas que podem acontecer contra eles.

O ensino das regras e a sensibilização dos indivíduos precisam ser estendidos a todos os profissionais envolvidos nesta assistência. Outras categorias já se preocuparam em questionar os sentimentos envolvidos neste tipo de atendimento. Em avaliação praticada com profissionais de enfermagem foi verificado alto grau de sensibilidade e aceitação das diversas situações de interrupção da gestação, entre as que concordavam em participar do atendimento às pacientes submetidas ao abortamento legal ${ }^{7}$.

Conclui-se que são importantes a inclusão deste tema nos cursos de especialização dos diversos profissionais envolvidos e a discussão constante do assunto em fóruns e congressos para disseminar o conhecimento das normas vigentes no país sobre o assunto, além de garantir a sensibilização dos profissionais.

No inquérito mencionado também foi apurado o aumento do número de médicos que entendem que a descriminalização do aborto em nosso país deveria ser discutida. Não existe padrão de comportamento único em relação à legalidade da realização da interrupção da gravidez; assim, países de um mesmo continente diferem quanto à aceitação das razões pelas quais as mulheres podem solicitar o abortamento . $^{8}$.

Diversos segmentos da população de diferentes países têm participado de discussões a respeito do abortamento e da necessidade de mudanças nas leis que regem os procedimentos envolvidos em sua assistência, mas, ainda hoje, se observam restrições na abordagem deste assunto. Os políticos preferem ignorá-lo por ter a convicção de que é polêmico e divide as opiniões dos eleitores. Este comportamento dos políticos foi verificado na Espanha, no período de 1979 a 2004, época em que o abortamento foi tema menos discutido pelos membros do parlamento quando comparado a outros assuntos de interesse das mulheres?

Talvez, a partir do envolvimento da comunidade médica, a difusão do conhecimento das complicações por abortamentos em condições não seguras possa determinar que a discussão do assunto atinja as autoridades responsáveis pela saúde no Brasil.

Neste inquérito também foi possível verificar que mais médicos são favoráveis à ampliação das razões pelas quais a interrupção da gravidez poderia ser aceita legalmente, e os autores ressaltam terem concluído que os médicos mostraram aumento na compreensão de que existem certas situações em que não se justifica obrigar a mulher a realizar o aborto na clandestinidade ou a colocar em perigo sua vida e sua saúde.

Os autores ressaltam que é importante esclarecer que não há indícios neste questionamento que permitam que se interprete ter havido aumento na porcentagem de médicos "a favor do aborto".

Em nossa ótica, a opinião dos médicos, de alguma maneira, se assemelha à referida pelos brasileiros em geral. Em inquérito realizado com mulheres não pertencentes a um grupo específico, foi observado que elas tendem a aceitar que os hospitais devem fazer os abortos que já estão previstos na lei e nas situações em que se colocam questões a respeito das condições físicas e mentais de vida da futura criança. Menor porcentagem de concordância foi verificada, entretanto, quando se tratou de avaliar os casos em que a justificativa para a realização do abortamento seria de ordem mais subjetiva como, por exemplo, quando a mulher se declara sem 
condições psicológicas para ter e criar o filho, ou quando a gravidez pode ser interpretada como conseqüência de possível negligência da própria mulher, como no caso da falha de método contraceptivo ${ }^{10}$.

As conotações culturais e religiosas em nosso país devem ser entendidas, e entre diversos níveis de profissionais de saúde já se encontrou também forte concepção moralista e religiosa como fator de resistência ao tema? Os profissionais da saúde, entretanto, devem ser sensibilizados para que suas opiniões pessoais não influenciem na garantia de atendimento humanizado às mulheres.

Este inquérito mostrou a importância do ensinamento continuado e que a estratégia da presença do tema em congressos, jornadas e afins (como tem acontecido) contribui para a sensibilização e formação de opinião em relação ao assunto aborto legal, embora ainda muito se tenha a fazer para garantir que os gineco-obstetras dêem às mulheres que passam por este problema o atendimento que solicitam e ao qual têm direito.

\section{Referências}

1. Colas OR, Andalaft Neto J, Rosas CF, Kater JR, Pereira IG. Aborto legal por estupro: primeiro programa público do país. Bioética. 1994;2(1):81-5.

2. Faúndes A, Bedone A, Pinto e Silva JL. I Fórum interprofissional para implantação do atendimento ao aborto previsto na lei: relatório final. Femina. 1997;25(1):69-71, 74-6, 78.

3. Faúndes A, Duarte GA, Andalaft-Neto J, Olivatto AE, Simoneti RM. Conhecimento, opinião e conduta de ginecologistas e obstetras brasileiros sobre o aborto induzido. Rev Bras Ginecol Obstet. 2004;26(2):89-96.

4. Faúndes A, Duarte GA, Osis MJD, Neto JA. Variações no conhecimento e nas opiniões dos ginecologistas e obstetras brasileiros sobre o aborto legal, entre 2003 e 2005. Rev Bras Ginecol Obstet. 2007; 29(4): 192-9.

5. Selli L. Os significados morais no Programa do Aborto Legal. Saúde Debate. 2004; 28(67): 118-29.
6. Lunardi VL, Simões AR. (Re)Ações da equipe de enfermagem frente a possibilidade de participação de um aborto legal. Rev Enfermagem UFR. 2004;12(2):173-8.

7. Blayo C. Access to abortion: the legal context, practice and frequency of recourse. Entre Nous Cph Den. 1993;(22-23):6-9.

8. Cambronero-Saiz B, Ruiz Cantero MT, Vives-Cases C, Carrasco Portino M. Abortion in democratic Spain: the parliamentary political agenda 1979-2004. Reprod Health Matters. 2007;15(29): 85-96.

9. Osis MD, Hardy E, Faúndes A, Alves G, Balarezo G. Opinião das mulheres sobre as circunstâncias em que os hospitais deveriam fazer abortos. Cad Saúde Pública. 1994;10(3):320-30.

10. Soares GS. Profissionais de saúde frente ao aborto legal no Brasil: desafios, conflitos e significados. Cad Saúde Pública. 2003;19 Supl 2:399-406. 